\title{
Characterization of Damage Evolution in an AM60 Magnesium Alloy by Computed Tomography
}

\author{
A. Waters, H. Martz, K. Dolan, M. Horstemeyer, D. Rikard, \\ R. Green
}

This article was submitted to

Ninth Annual Symposium on Nondestructive Characterization of Materials, Sydney, Australia, June 28-July 2, 1999

\section{June 16, 1999}

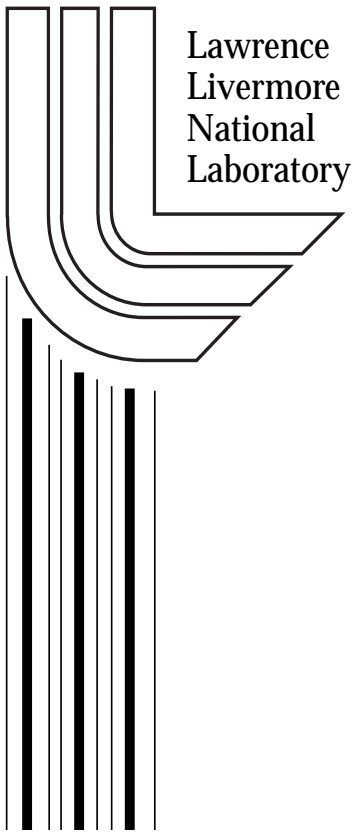




\section{DISCLAIMER}

This document was prepared as an account of work sponsored by an agency of the United States Government. Neither the United States Government nor the University of California nor any of their employees, makes any warranty, express or implied, or assumes any legal liability or responsibility for the accuracy, completeness, or usefulness of any information, apparatus, product, or process disclosed, or represents that its use would not infringe privately owned rights. Reference herein to any specific commercial product, process, or service by trade name, trademark, manufacturer, or otherwise, does not necessarily constitute or imply its endorsement, recommendation, or favoring by the United States Government or the University of California. The views and opinions of authors expressed herein do not necessarily state or reflect those of the United States Government or the University of California, and shall not be used for advertising or product endorsement purposes.

This is a preprint of a paper intended for publication in a journal or proceedings. Since changes may be made before publication, this preprint is made available with the understanding that it will not be cited or reproduced without the permission of the author.

This report has been reproduced

directly from the best available copy.

Available to DOE and DOE contractors from the

Office of Scientific and Technical Information

P.O. Box 62, Oak Ridge, TN 37831

Prices available from (423) 576-8401

http://apollo.osti.gov/bridge/

Available to the public from the

National Technical Information Service

U.S. Department of Commerce

5285 Port Royal Rd.,

Springfield, VA 22161

http://www.ntis.gov/

OR

Lawrence Livermore National Laboratory

Technical Information Department's Digital Library

http://www.llnl.gov/tid/Library.html 


\title{
Characterization of Damage Evolution in an AM60 Magnesium Alloy by Computed Tomography
}

\author{
Amy Waters*, Harry Martz ${ }^{\dagger}$, Ken Dolan ${ }^{\dagger}$, Mark Horstemeyer** \\ Derrill Rikard ${ }^{\dagger}$ and Robert Green* \\ *Center for Nondestructive Evaluation, 3400 N. Charles St., Baltimore, MD 21218. \\ ${ }^{\dagger}$ Lawrence Livermore National Laboratory, P.O. Box 808, Livermore, CA 94550 \\ **Sandia National Laboratories, 7011 East Ave., Livermore, CA 94550
}

\begin{abstract}
Lawrence Livermore National Laboratory (LLNL) and Sandia National Laboratories, California (SNL) are collaborating on the development of new techniques to study damage evolution and growth in material specimens subjected to mechanical loading. These techniques include metallography, radiography, computed tomography (CT) and modeling. The material specimens being studied include cast magnesium and aluminum alloys, and forged stainless steel. We will concentrate on characterizing monotonically loaded magnesium alloy specimens using computed tomography. Several notched tensile specimens were uniaxially loaded to different percentages of the failure load. Specimens were initially characterized by radiography and computed tomography to determine the preloaded state. Subsequent CT scans were performed after the samples were loaded to different percentages of the load failure. The CT volumetric data are being used to measure void size, distribution and orientation in all three dimensions nondestructively to determine the effect of void growth on the mechanical behavior of the materials.
\end{abstract}

\section{INTRODUCTION}

There has been increasing interest from the automotive industry to improve the performance of cast metals used in automotive components. To improve the performance and design of components, it is necessary to understand the behavior of these materials; in particular to understand damage evolution that occurs when materials undergo loading. Specifically, this project is focusing on understanding and predicting damage evolution due to monotonic loading in cast AM60 magnesium alloy tensile bar specimens. Accumulation of damage during monotonic loading in ductile metals is almost always due to nucleation, growth and coalescence of voids $(1,2)$. Cast metals contain voids initially due to the casting process. The size, shape, distribution and orientation of these voids will affect the damage growth that occurs in the material during loading. To date, numerous models have been developed to predict damage growth $(3,4,5)$ and experiments have been done to study damage after loading. However, to our knowledge there has not been a quantitative link established between predictions and experiments. 
A nondestructive characterization technique is necessary to characterize the internal structure of the cast parts since we are evaluating specimens before, at intervals during monotonic loading, and after loading. We have selected the NDE xray imaging method of computed tomography (CT) to evaluate damage growth, e.g., void growth, nucleation and coalescence, in $\mathrm{Mg}$ alloy tensile bar specimens at different percentages of the failure load. This information will be input to constitutive equations of material models, and finite element analysis (FEA) will be performed to simulate in-service performance.

\section{MATERIALS}

In an attempt to meet current and future fuel economy standards, US automobile producers are developing structures and components for cars of lighter mass materials. Magnesium is the lightest of the structural metals with a density of 1.74 $\mathrm{g} / \mathrm{cm}^{3}$, and hence much research is being focused on its applications by the automotive industry. The magnesium alloy we are studying is AM60, containing 6\% aluminum and $0.15 \%$ manganese by weight. The tensile bars, obtained from the Institute of Magnesium Technology in Quebec, Canada, were cast using a cold chamber die casting machine with a 600-ton locking force and an injection temperature of 675 to 690 Celsius. We have three specimens each with three different notch geometries for a total of nine tensile bar specimens. The notch radii of these samples are $0.635,0.794$, and $1.27-\mathrm{cm}$. Each tensile bar has a maximum outer diameter of 1.3-cm (see Figure 1).

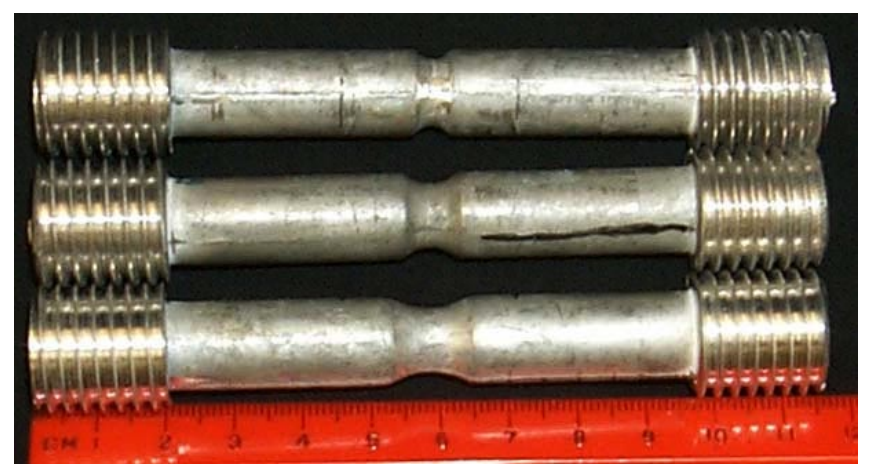

FIGURE 1. Tensile bar specimens with three different notch radii; top, 0.635-cm; middle, 0.794-cm; bottom, 1.27-cm. All bars are approximately $11.8-\mathrm{cm}$ in length, with a maximum outer diameter of approximately $1.3-\mathrm{cm}$. 
TABLE 1. Ultimate tensile strengths (UTS) and calculated percentages of the load failures for each notch geometry.

\begin{tabular}{ccccc}
\hline $\begin{array}{c}\text { Notch Radius } \\
(\mathbf{c m})\end{array}$ & $\begin{array}{c}\sigma_{\text {UTS }} \\
(\mathbf{M P a})\end{array}$ & $\begin{array}{c}\mathbf{6 0 \%} \text { load } \\
(\mathbf{N})\end{array}$ & $\begin{array}{c}\mathbf{8 7 \%} \text { load } \\
(\mathbf{N})\end{array}$ & $\begin{array}{c}\mathbf{9 3 \%} \text { load } \\
(\mathbf{N})\end{array}$ \\
\hline 0.635 & 207 & 9176 & 13304 & 14225 \\
0.794 & 221 & 9283 & 13460 & 14389 \\
1.27 & 241 & 9879 & 14327 & 15314 \\
\hline
\end{tabular}

\section{MECHANICAL LOADING}

Approximate load failure levels for monotonic tension were previously determined for the three different notch geometries at Westmoreland Mechanical Testing in Pennsylvania. The ultimate tensile strengths for the three different notch geometries are presented in Table 1. From this data, it was decided to load each sample at Sandia National Laboratories, California, using an MTS 50 kip multi-turn loading frame to $60 \%, 87 \%$, and $93 \%$ of failure load, and finally to failure. Samples are loaded at a displacement rate of $0.0005-\mathrm{cm} / \mathrm{sec}$. After each loading, the samples are rescanned and CT data collected and analyzed. Load-displacement curves are acquired for each sample loading.

\section{BACKGROUND OF CT AND EXPERIMENTAL PARAMETERS}

Initially, film radiographs were acquired of the magnesium tensile bars. These radiographs revealed internal features including voids, inclusions and cracks. However, single-projection radiography hides crucial information: the overlapping of internal features obscures parts of these features, and their depth remains unknown. CT technology is capable of retrieving complete three-dimensional (3-D) information. It involves acquiring multiple radiographic images of the sample object at different angles, using electronic imaging detectors and processing the projections in a computer. The final 3-D image, generated by mathematically combining these images, is a map of the linear attenuation coefficient and gives the relative locations and dimensions of features within the object as well as external details (6). We have several different CT systems available to us at LLNL. We investigated two different CT systems developed at LLNL, known as PCAT (450-kV source) and KCAT (160$\mathrm{kV}$ source). Both of these systems use a scintillator $\left(\mathrm{Tb}_{2} \mathrm{O}_{3}\right.$ doped) coupled by an optical lens to a CCD camera detector. We studied varying several parameters in an effort to optimize the CT data. The CT systems and a few of the parameters varied are presented in Table 2.

We are acquiring all $\mathrm{CT}$ data using KCAT with the parameters indicated in the bottom row of Table 2. Although the modulation transfer function (MTF) for this 
TABLE 2. Parameters investigated to optimize two CT systems for analysis of Mg tensile bars.

\begin{tabular}{|c|c|c|c|c|c|c|c|c|c|c|}
\hline $\begin{array}{l}\text { CT } \\
\text { Sys. }\end{array}$ & $\mathrm{kV}$ & $\mathbf{m A}$ & $\begin{array}{l}\text { Spot } \\
\text { Size }\end{array}$ & $\begin{array}{l}\operatorname{sod}^{1} \\
(\mathbf{m m})\end{array}$ & $\begin{array}{l}\text { odd }^{2} \\
(\mathbf{m m})\end{array}$ & $\begin{array}{l}\text { Thick/ } \\
\text { Scint. }\end{array}$ & CCD & Filter & $\begin{array}{l}\text { Acq. } \\
\text { Time }\end{array}$ & $\begin{array}{c}\text { MTF } \\
10 \mathrm{lp} / \mathrm{mm}^{4}\end{array}$ \\
\hline PCAT & $\frac{200}{75}$ & 10.0 & $\begin{array}{l}1 \mathrm{~mm} \\
\text { (o.d.) }\end{array}$ & 1482 & 23 & $\begin{array}{c}\begin{array}{c}6-\mathrm{mm} \\
\text { plate }\end{array} \\
12-\mathrm{mm} \\
\text { f.o. }\end{array}$ & $\begin{array}{c}1024 \mathrm{x} \\
1024 \\
\text { pixels } \\
14 \mathrm{bits}\end{array}$ & none & $\begin{array}{c}\sim 25 \\
\text { hours }\end{array}$ & N/A \\
\hline \multirow[t]{2}{*}{ KCAT } & \multirow[t]{2}{*}{75} & \multirow[t]{2}{*}{0.12} & \multirow{2}{*}{$\begin{array}{c}10 \mu \mathrm{m} \\
\text { (o.d) }\end{array}$} & \multirow[t]{2}{*}{77} & \multirow[t]{2}{*}{15} & $\begin{array}{l}\begin{array}{c}2-\mathrm{mm} \\
\text { plate }\end{array} \\
\end{array}$ & $\begin{array}{c}768 \mathrm{X} \\
512, \\
\text { nivel }\end{array}$ & none & \multirow{2}{*}{$\begin{array}{c}\sim 5 \\
\text { hours }\end{array}$} & $\sim 0.70$ \\
\hline & & & & & & $\begin{array}{l}\text { 3-mm } \\
\text { f.o. }^{3}\end{array}$ & $\begin{array}{l}\text { pixels } \\
12 \text { bits }\end{array}$ & $\begin{array}{c}.076 \\
\mathrm{~mm} \mathrm{Al} \\
\end{array}$ & & $\sim 0.52$ \\
\hline
\end{tabular}

${ }^{1}$ source-to-object distance, ${ }^{2}$ object-to-detector distance, ${ }^{3}$ fiber optic, ${ }^{4}$ line-pairs $/ \mathrm{mm}$

detector configuration was somewhat lower than that of other configurations we investigated, the fiber optic scintillator plate appeared to contain fewer large noticeable defects (such as dark spots, patterns, and internal bubbles), which results in fewer artifacts in the reconstructed CT slices. We acquired 360 radiographic projections over 180 degrees. All data is acquired using the same scan parameters. The projections are converted into sinograms and preprocessed to eliminate artifacts such as rings, caused by an imbalance in the detector elements, and beam hardening, which is a result of the preferential absorption of low energy x-rays. The sinograms are then reconstructed into slices using a convolution-back-projection algorithm and merged into a 3-D volume of 768 X 768 X 512 pixels with voxel dimensions $0.02 \mathrm{x}$ $0.02 \times 0.02 \mathrm{~mm}^{3}$. One digital radiograph, or projection, of the notched region of an unloaded sample is shown in Figure 2, as well as two reconstructed CT slices from the notched region.
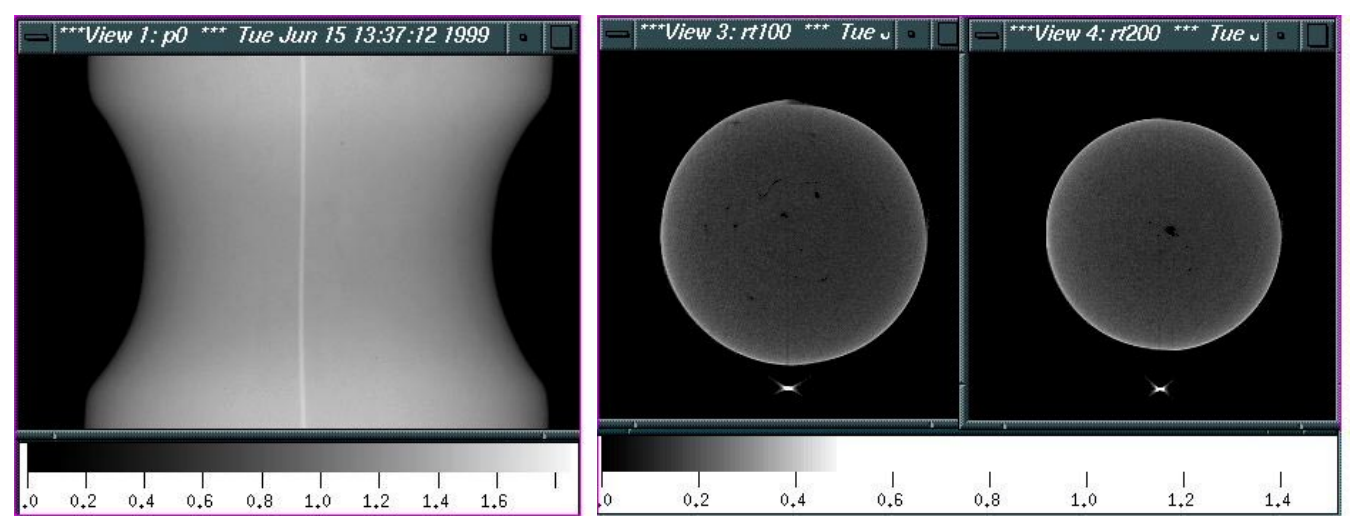

FIGURE 2. Representative radiographic and tomographic data. Left: digital radiograph of the notched area of one tensile bar $(0.794-\mathrm{cm})$ including a fiducial wire. Middle: reconstructed CT slice from the upper section of the notch; Right: CT slice from the middle section of the notch. Note voids (dark spots) are visible in both CT slices. The light ring on the outside of the slices is due to the beam hardening artifact. The gray scale relates gray tones to relative attenuation in $\mathrm{mm}^{-1}$ units.

\section{RESULTS AND ANALYSIS}


Data has been collected for all nine specimens in their initial, pre-loaded state. These data have been reconstructed into 3-D volumes and are being analyzed using $\mathrm{IDL}^{1}$. For each data set, the initial void size and distribution are quantified, as well as void orientation along all 3 axes $(\mathrm{x}, \mathrm{y}$, and $\mathrm{z}$ ). We are using a method known as "morphological granulometry" $(7,8,9)$. This method can be described as follows. If we consider a large collection of 'grains' of different sizes filtered through sieves of progressively increasing mesh sizes, the numerical characteristics of the residues at each stage can be measured until nothing remains. The resulting residues from each filter provide a quantitative measure of the grain size distribution. By varying the size, shapes and orientations of the mesh elements in the sieves it is possible to get a complete quantitative morphological characterization of the grains. Codes have been developed at LLNL using IDL to quantify porosity based on morphological granulometry (10). The technique will be used on all samples to quantify the initial porosity as well as porosity after each loading. All specimens have been loaded to $60 \%$ of load failure (one tensile bar with notch radius $0.794 \mathrm{~cm}$ failed at the grip under initial loading) and a representative tensile bar from each notch geometry has been rescanned. Representative slices of the same area of one tensile bar $(0.794-\mathrm{cm}$ notch radius) are shown in Figure 3 before and after loading to $60 \%$ of the failure load. Note, there is no detectable visual difference between the slices before and after loading. This illustrates the need to evaluate 3-D volumes more quantitatively with software programs capable of detecting changes not clearly visible with the naked eye.

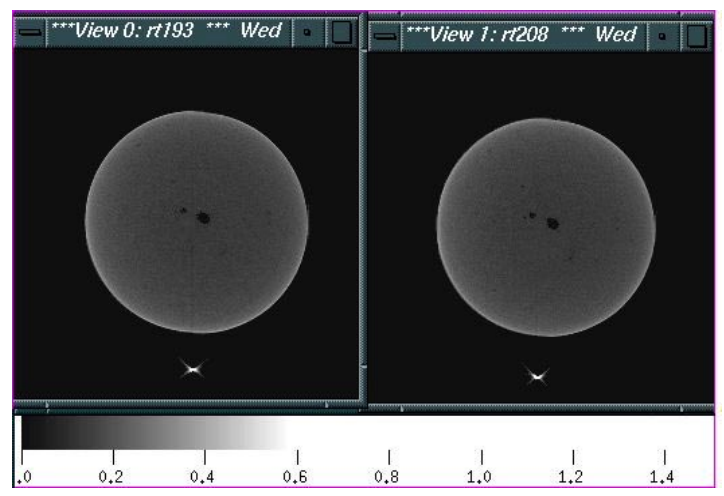

FIGURE 3. CT slices from one tensile bar (0.794-cm notch radius) before (left) and after (right) loading to $60 \%$ of the failure load. Note there are no visually obvious changes in void size, orientation or distribution. The gray scale relates gray tones to relative attenuation in $\mathrm{mm}^{-1}$ units.

\section{SUMMARY AND FUTURE WORK}

We have acquired CT data on all nine samples in their initial, preloaded state. This data is being reconstructed into 3-D volumes and the void volume fraction, size, distribution and orientation along the $\mathrm{x}, \mathrm{y}$ and $\mathrm{z}$ axes are being determined. All nine samples have been loaded to $60 \%$ of their respective failure loads and CT data collection has begun. We will continue to load the samples and collect CT data at

\footnotetext{
${ }^{1}$ This is not an endorsement of this software package.
} 
$87 \%, 93 \%$ and failure. The void analysis will be done at all load levels and input into material models being developed at Sandia National Laboratories, California. The CT data will then be segmented, surface extracted, meshed and used as input to FEA codes. FEA predictions can then be compared to experimental data and material models can be modified as needed. This method, incorporating experimental data with comparisons to FEA model predictions will help to validate material models as well as provide more accurate information about damage evolution in materials under loading conditions.

\section{ACKNOWLEDGEMENTS}

The authors would like to thank Earl Updike, LLNL, for acquiring PCAT Mg data; Jean Renaud, IMT, Quebec, Canada, for providing the cast magnesium samples; Bonnie Antoun, Sandia National Laboratories, California, for acquiring tensile loading information; Jim Sudy, Westmoreland Mechanical Testing, Pennsylvania, for acquiring load failure data. This work is performed under the auspices of the U.S. Department of Energy by LLNL under contract W-7405-ENG-48.

\section{REFERENCES}

1. Cocks, A.C.F. and Ashby, M. F., Prog. Mater. Sci. 27, 189-244 (1982).

2. Garrison, W. M. and Moody, N. R., J. Phys. Chem. Solids. 48, 1035-1074 (1987).

3. McClintock, F. A., ASME J. Appl. Mech. 35, 363 ( 1968).

4. Gurson, A. L., J. Engng. Materials Thechn. 99, 2-15 (1977).

5. Horstemeyer, M. F., and Gokhale, A. M., "A Void Nucleation Model for Ductile Materials", accepted by Internal J. Solids and Structures.

6. Kak, A. C. and Slaney, M., Principles of Computerized Tomographic Imaging, New York: IEEE Press, 1988.

7. Matheron, G., Random Sets and Integral Geometry, New York: John Wiley Press, 1975.

8. Serra, J., Image Analysis and Mathematical Morphology, New York: Academic Press, 1982.

9. Giardina, C. R. and Dougherty, E. R., Morphological Methods in Image Processing, Englewood Cliffs, NJ: Prentice-Hall, 1988.

10. Sengupta, S. K., IMAN-3D: A Software tool-kit for 3-dimensional image analysis, Center Report, Engineering Research, Development and Technology. Livermore, CA: Lawrence Livermore National Laboratory, UCRL-53868-98 (1999). 